\title{
The lifecycle of hedge funds
}

\section{Dieter Kaiser}

Feri Institutional Advisors GmbH, Haus am Park, Rathausplatz 8-10, Bad Homburg 61348, Germany.

Tel: + 49 (6172) 916 3712, Fax: + 49 (6172) 916 1700, E-mail: dieter.kaiser@feri.de

Received (in revised form): 28th January, 2008

Dr Dieter Kaiser is Director Hedge Funds at Feri Institutional Advisors GmbH in Bad Homburg, Germany where he is responsible for managing hedge funds portfolios. From 2003 to 2007 he was responsible for institutional research at Benchmark Alternative Strategies GmbH in Frankfurt, Germany. He has written numerous articles on hedge funds that have been published in both, academic and professional journals and is the author and editor of seven books. Dieter Kaiser holds a BA in Business Administration from the University of Applied Sciences Offenburg, an MA in Banking and Finance from the Frankfurt School of Finance and Management, and a PhD in Finance from the Chemnitz University of Technology. On the academic side, he is a research fellow at the Centre for Practical Quantitative Finance of the Frankfurt School of Finance and Management.

\section{Practical applications}

This paper helps institutional investors, pension funds, and endowments to understand why the risk-adjusted performance of hedge funds, especially for nondirectional strategies, decreases over time and provides a framework that can be used to analyse where the funds are in their lifecycle. This is important because institutional investors are often perceived to be long-term investors in hedge funds.

Journal of Derivatives \& Hedge Funds, Vol. 14 No. 2, 2008, pp. 127-149 (C) 2008 Palgrave Macmillan Ltd $1753-9641$

\section{Abstract}

Hedge fund managers proclaim that they predominantly use investment strategies that generate profit from misvalued market instruments. Regarding efficient market theories, hedge funds use market price anomalies and hence serve to increase market efficiency. Especially with arbitrage-based strategies, however, in highly competitive markets it is possible that excess returns will vanish over time because other investment managers will 'jump on the bandwagon', and trade similar inefficiencies, thus diminishing risk premiums. Hedge fund excess returns will naturally decrease over time. The thesis that hedge funds develop according to this pattern is called the lifecycle theory of hedge funds'. This paper empirically investigates the lifecycle theory based on an extensive database of 1,433 hedge funds for the period January 1996 until May 2006. We verify that hedge funds indeed follow a lifecycle. Journal of Derivatives \& Hedge Funds (2008) 14, 127-149. doi:10.1057/jdhf.2008.11

Keywords: hedge funds; lifecycle; omega; fund age

\section{INTRODUCTION}

Hedge funds either (1) identify and profit from incorrectly valued securities by applying 
different investment strategies, or (2) earn alternative, that is, noncommon, risk premiums. Many definitions exist for the term 'hedge funds'. We characterise hedge funds as weakly regulated collective investment products that invest in cash, equity, fixed income, commodities, and derivatives markets to generate profit for investors, using leverage to a certain extent. Any active investment strategies they may use are oriented primarily toward the fund manager's specific skills, and are absolute return-based, incorporating short-selling strategies. Nevertheless, hedge fund risk and return targets are quite heterogeneous.

Hedge fund managers often proclaim they are using investment strategies to generate profit from misvalued instruments ('arbitrage'). Thus, they are really just taking advantage of temporary price discrepancies in fundamental values. In practice, arbitrage means purchasing cheaper instruments at one exchange, and simultaneously selling them at another for a profit. As per Fama's ${ }^{1}$ efficient market theory, hedge funds use market price anomalies to increase market efficiency.

With arbitrage-based strategies, it is feasible that hedge funds will generate above-average risk-adjusted returns, at least in the early years, until the traded inefficiencies and investment techniques are sufficiently familiar to the market. If the investment strategies prove successful, other investment managers will emulate them and trade similar inefficiencies, thus leading to decreasing risk premiums according to Jevons's ${ }^{2}$ law of uniform prices. In the context of Vernon's ${ }^{3}$ product lifecycle theory, this could mean that hedge funds with respective investment strategies as well as within the different kinds of traded inefficiencies are also subject to a cycle.
Another aspect also leads to hedge fund lifecycles. It is postulated that hedge fund managers generate ideas partly from analysing historical return patterns. If the financial world follows a trend, creating a hedge fund can be interpreted as 'joining the bandwagon', thus generating excess returns as long as the trend remains intact. When the trend weakens, however, the excess returns decrease as well, and may become losses unless another trend is detected or the fund is closed down. Hedge fund strategy types that do not specialise in discovering new trends early and regularly should demonstrate a distinct lifecycle.

The goal of this paper is to model and empirically verify a hedge fund lifecycle. We investigate the lifecycle theory based on an extensive database of 1,433 hedge funds for the period January 1996 through May 2006. We calculate different statistical variables for individual funds, and compare them with the respective peer groups. We then analyse the statistical significance of the variables fund age and number of phases to determine their influence on the lifecycle.

The next section provides three hypotheses and develops the theoretical hedge fund lifecycle model, which is based on Keating/Shadwick's ${ }^{4}$ omega measure. The subsequent section presents the database, while the penultimate section contains the verification process for the hypotheses and gives our empirical results. The final section summarises the results and our conclusions.

\section{HEDGE FUND LIFECYCLE MODEL}

One of the central questions in finance is why the reward structures of financial intermediates in the economy are so high despite high 
competition and the uncertain value of their activities. This question is even more puzzling when we consider that many studies have found that mutual fund managers are unable to consistently outperform their benchmarks. ${ }^{5}$ And this problem exists with hedge funds as well, because their fees are dramatically higher. Hence, it is understandable that the factors influencing performance and performance persistence constitute a large part of the academic hedge fund literature.

In studying different hedge fund strategies, Agarwal and $\mathrm{Naik}^{6}$ find a significant persistence of loser funds continuing to lose. Capocci et al. ${ }^{7}$ find performance persistence predominantly in average or below-average hedge funds. Hence poor performance is a crucial factor in hedge fund mortality.

Harri and Brorsen ${ }^{8}$ conclude that performance persistence predominates in the hedge fund strategies equity market neutral, fund of funds, event driven, and global macro. Brown et al. ${ }^{9}$ and Kat and Menexe, ${ }^{10}$ however, find very little evidence for performance persistence in hedge funds. According to Agarwal and Naik, ${ }^{11}$ hedge fund performance persistence is strong when performance is considered on a quarterly basis. On a yearly basis, however, it tends to decrease, thus indicating the short-term character of individual hedge funds.

Furthermore, Edwards and Caglayan ${ }^{12}$ identify a performance persistence in hedge funds with extreme performance swings, either very high or very low.

According to Boyson and Cooper, ${ }^{13}$ performance persistence predominantly occurs with new or relatively younger hedge funds. Baquero et al. ${ }^{14}$ conclude that, on a quarterly basis, there is a very high probability that 20-30 per cent of the funds outperforming in one- quarter will continue to do so in the next quarter. The authors find the same result on a yearly basis.

Based on these empirical results, it makes sense to rank hedge fund managers along a hedge fund lifecycle continuum that includes their changing structures, income cash flows, and motivations over time and as fund size increases. Several researchers have concluded that, statistically, younger hedge funds outperform more mature ones ${ }^{15}$ (see Liang, ${ }^{16}$ Schneeweis et al., ${ }^{17}$ Amenc et al., ${ }^{18}$ and Kaiser and Kisling ${ }^{19}$ ).

Howell $^{20}$ concludes that the youngest 10 per cent of hedge funds outperforms the oldest 10 per cent by 9.70 per cent every year, after accounting for any possible survivorship bias.

There are a number of reasons for the statistical outperformance of young hedge funds. It may be that managers in their early years are more likely to seek out innovative market price anomalies that other participants have not yet grasped and which are not yet included in prices. We, however, assume that as new competitors enter the market, any possible profits from price anomalies will diminish. And, in accordance with arbitrage theory, incorrect valuations will vanish over time.

At the same time, however, many hedge fund managers begin their careers trading for investment banks or in other hedge funds. This means managing smaller markets, which usually have lower liquidity. Providing liquidity in a tight market is a successful return generator of many hedge fund strategies.

Thus, new hedge funds are predominantly founded in new markets to take advantage of market price anomalies, and over time it is assumed that the increasing competition will increase market efficiency, and decrease profits. 
The pioneers of those strategies, however, should be able to generate above-average riskadjusted returns compared with their peer group for several months or years.

Note also that hedge funds in their early years are smaller and can be more flexible in their decision making. Established funds usually manage numerous strategies with a large trading team, as well as internal risk management, compliance, and investor relations departments. Their assets under management may total hundreds of millions or even $\$ 1$ billion. But the resulting bureaucracy can cause these companies to lose their entrepreneurial edge. $^{21}$

In contrast, hedge funds in their early years tend to outsource many services so management can concentrate solely on managing assets. ${ }^{22}$ With smaller and more efficient structures come quicker investment decisions, which can directly influence the trading room and make it easier to take immediate advantage of market price anomalies.

Note also that as fund size increases, larger positions must be traded. ${ }^{23}$ But trading larger positions in less liquid markets can result in higher costs and decreased profits. This is especially true for hedge funds that operate in special niches in capacity-sensitive or less liquid markets. In other words, certain transactions may only be profitable when executed in low volumes. ${ }^{24}$

Harri and Brorsen, ${ }^{8}$ Agarwal et al., ${ }^{25}$ Goetzmann et al., ${ }^{26}$ Getmansky, ${ }^{27}$ Ammann and Moerth, ${ }^{28}$ and Fung et al. ${ }^{29}$ have found that hedge fund profits decrease as market capitalisation increases. ${ }^{30}$ According to Berk and Green's $^{31}$ rational model of active portfolio management, decreasing returns in poorly performing funds lead to fund transfers into better performing funds, and thus helps decrease performance over time. From this, we obtain our first hypothesis:

Hypothesis 1: Risk-adjusted returns of single hedge funds decrease over time.

Hedge funds can be classified according to whether they follow directional or nondirectional strategies. Following Jevons's ${ }^{2}$ law of one uniform price, every arbitrage possibility is available for only a limited amount of time. Inefficiencies attract other market participants who are also trying to take advantage of them, which ultimately causes the inefficiencies to disappear. Since nondirectional strategies draw their returns more from arbitrage profits and less from market direction movements, we expect the nondirectional strategies group to have a shorter lifecycle than the directional strategies group. Thus our second hypothesis:

Hypothesis 2: Risk-adjusted returns of nondirectional hedge fund strategies decrease more quickly than those of directional hedge fund strategies.

There are also several reasons from a psychological standpoint that hedge fund managers in their early years would be more motivated to generate superior risk-adjusted returns. These may include the entrepreneurial spirit of a young business, or the necessity of reaching a certain level of capital to break even.

In practice, we note that, in earlier years, company cultures are often characterised by a strong team spirit and hard work. These tendencies may be lost with increasing investor fund inflows. At the same time, the psychological motivation of individuals to start a successful 
hedge fund company should not be underestimated. With increasing assets under management and a certain level of wealth, the number of working hours typically decreases. This degree of saturation could be an explanation for decreasing risk-adjusted returns over time.

At the same time, we note that it is possible that some hedge funds will manage to consistently achieve above-average risk-adjusted performance. The number of funds that manage to extend their 'lifecycle' beyond the average is, however, relatively small. According to De Figueiredo and Budhraja, ${ }^{32}$ innovation is one of the main reasons hedge funds find themselves on top for several years. Hence, in the context of a hedge fund lifecycle, it is important to determine whether the innovation power of individual funds or the industry as a whole will continue.

To answer this question, we consider two main models concerning the innovation capacity of industries or economies over time:

- The 'fishing-out' model: Eicher and $\mathrm{Kim}^{33}$ posit that all simple innovations are completed relatively quickly and with minor effort. More difficult problems require more resources (workload and funds), and are solved later. Therefore, every successive improvement is harder than the last one.

- The 'standing on shoulders' model: This model from Jones ${ }^{34}$ states that every innovation motivates another innovation. Building on this, Jones argues that the present will not represent the future because unpredictable innovations will increase productivity and thus economic growth. In this framework, innovation accelerates with the amount of ideas and innovations take place with increasing frequency.
For the hedge fund industry, the "standing on shoulders' model seems the most suitable. The fact that innovation takes time, however, implies that hedge funds can have several phases of either below- or above-average returns during their lifecycles. Thus, due to the higher difficulty of detecting new market inefficiencies, we posit that nondirectional strategies experience fewer growth and contraction phases than directional strategies. Thus, our third hypothesis is

Hypothesis 3: Hedge funds following a directional strategy experience more growth and contraction phases than those following a nondirectional strategy.

The end of a hedge fund lifecycle involves one of the following steps: (1) The hedge fund manager ceases business operations, (2) riskadjusted performance stagnates at a low level after initial success, or (3) the hedge fund manager adapts his strategy and manages to repeat his earlier success. Owing to the short individual fund track records currently available for the hedge fund industry, it is difficult to generate empirical evidence for the end of a hedge fund lifecycle. In this paper, we focus on the first years.

Our first step in modelling the hedge fund lifecycle is to choose the variable for our analysis. Because of the specific distribution properties of hedge fund return time series with regard to higher moments, it can be problematic to use the rate of return, correlation, the Sharpe ratio, or value at risk. Thus, we choose the twodimensional omega measure for our model, which includes the specific distribution properties of hedge funds.

According to Keating and Shadwick, ${ }^{4}$ the omega measure is a modern variable, developed 
with the specific needs of the hedge fund industry in mind. The omega measure thus includes the higher moments of a distribution. It is also a function of the individual expected return threshold $R_{\min }$ of an investor, and requires no distribution assumptions. Hence, we choose a minimum return $R_{\min }$, which separates the return distribution into two parts. Returns below the minimum are classified as losses and those above are considered profits. Omega defines the ratio of profits to losses, and can be stated as follows: ${ }^{4}$

$$
\Omega\left(R_{\min }\right)=\frac{I_{2}\left(R_{\min }\right)}{I_{1}\left(R_{\min }\right)}
$$

where $\Omega\left(R_{\min }\right)=$ the omega measure, relative to $R_{\text {min }}, I_{1}\left(R_{\text {min }}\right)=\int_{a}^{R_{\text {min }}} F(x) \mathrm{d} x, I_{2}\left(R_{\text {min }}\right)=$ $\int_{R_{\text {min }}}^{b}(1-F(x)) \mathrm{d} x, R_{\text {min }}$ is the the profit threshold, and $a, b$ are the lower and upper boundaries of the return distribution.

$F(x)$ represents the return distribution function of the fund. Omega represents the ratio of probability-weighted profits and losses with regard to threshold $R_{\min }$. The quality of an investment is measured according to whether it has realised at least a return of $R_{\min }$. The omega measure is thus the ratio of two cumulative density functions. It gives the chance of excess return per unit of shortfall risk for a chosen target return.

Generally, the investment with a higher omega is chosen independently from the minimum return threshold, because the reward for risk taken is higher. ${ }^{35}$

Schneeweis et al. ${ }^{36}$ show that formula (1) can be rewritten as follows:

$$
\Omega\left(R_{\min }\right)=\frac{C\left(R_{\min }\right)}{P\left(R_{\min }\right)}
$$

where $C\left(R_{\min }\right)$ is the price of a European call option on the investment and $P\left(R_{\min }\right)$ is the price of a European put option on the investment. The maturity of both options is one period (eg one month) and the strike price of both is $R_{\min }$. Thus the denominator and numerator of the omega measure can be written as follows:

$$
\begin{aligned}
\int_{R_{\text {min }}}^{b} & {\left[1-F\left(R_{t}\right)\right] \mathrm{d} R_{t} } \\
= & \int_{R_{\text {min }}}^{b}\left(R_{t}-R_{\text {min }}\right) f\left(R_{t}\right) \mathrm{d} R_{t} \\
= & E\left[\max \left(R_{t}-R_{\text {min }}, 0\right)\right] \\
\int_{a}^{R_{\text {min }}} & F\left(R_{t}\right) \mathrm{d} R_{t} \\
= & \int_{a}^{R_{\text {min }}}\left(R_{\text {min }}-R_{t}\right) f\left(R_{t}\right) \mathrm{d} R_{t} \\
= & E\left[\max \left(R_{\text {min }}-R_{t}, 0\right)\right]
\end{aligned}
$$

where $f\left(R_{t}\right)$ is the density function of the oneperiod return. Equations (3) and (4) represent nondiscounted call and put prices. To calculate net present value, we multiply both sides by $\exp \left(-R_{f}\right)$, where $R_{f}$ is the riskless interest rate of the period. These results concur with $C\left(R_{\min }\right)$ and $P\left(R_{\min }\right)$, as per formulas:

$$
C\left(R_{\min }\right)=\mathrm{e}^{-R_{f}} E\left[\max \left(R_{t}-R_{\min }, 0\right)\right]
$$

$$
P\left(R_{\min }\right)=\mathrm{e}^{-R_{f}} E\left[\max \left(R_{\min }-R_{t}, 0\right)\right]
$$

We can calculate the omega measure empirically according to the partial moments 
method as follows:

$$
\Omega\left(R_{\min }\right)=\frac{1 / T \sum_{t=1}^{T} \max \left(R_{t}-R_{\min }, 0\right)}{1 / T \sum_{t=1}^{T} \max \left(R_{\min }-R_{t}, 0\right)}
$$

where $T$ is the number of observations, $R_{\min }$ the minimum return threshold, and $R_{t}$ is the return of the individual hedge fund in month $t$ $(t=1, \ldots, T)$.

Again, the investment with a higher omega is chosen independently from the minimum return threshold, because the reward for risk is higher.

To represent an actual lifecycle, we consider the performance of the underlying hedge funds independently from the actual month. Thus, we first set the performance of all funds in the database to starting month 1 , which represents the first month of all hedge funds in our sample, independent of the effective month at that time. ${ }^{37}$

In this investigation, we define a fixed profit threshold $R_{\text {min }}$, and assume the value of the omega measure with respect to this threshold as a rank.

Because we intend to rank the individual hedge funds, we now consider the omega measure with a specific profit threshold as opposed to the omega function over the entire bandwidth of returns. ${ }^{4}$ For empirical investigations, Bertrand and Prigent recommend choosing an $R_{\min }$ of between 0 per cent and the riskless interest rate. The arithmetic mean of the riskless interest rate based on USD three-month Libor for our sample period is 4.07 per cent. Thus we choose $R_{\min }=2$ per cent as the simplified mean of these two values.

To model the hedge fund lifecycle, it is not advisable to consider statistics for the entire sample period. So we use the rolling calculation method to determine the dynamic course of the omega measure. In our first step, we calculate the 12-month rolling omega measure for all hedge funds in the database at time $i$ with $R_{\min }=2$ per cent as follows:

$$
\Omega\left(R_{\min }\right)_{i}=\frac{1 / 12 \sum_{t=i-11}^{i} \max \left(R_{t}-2 \%, 0\right)}{1 / 12 \sum_{t=i-11}^{i} \max \left(2 \%-R_{t}, 0\right)}
$$

To compare the hedge funds in the database with their peer group, we need a benchmark time series. We construct this time series by calculating the median of the 12-month rolling omega measure for all hedge funds in the respective peer group for each month. Each month's benchmark omega measure represents the median of the 12-month rolling omega measure for the respective peer group in that month as follows:

$$
\begin{gathered}
\Omega\left(R_{\text {min }}\right)_{i}^{B M}=\tilde{\Omega}\left(R_{\min }\right)_{i}^{B M} \\
\tilde{\Omega}\left(R_{\text {min }}\right)_{i}^{B M}= \begin{cases}\Omega\left(R_{\text {min }}\right)_{i,(n+1) / 2} & n \text { even } \\
\frac{1}{2}\left(\Omega\left(R_{\text {min }}\right)_{i,(n / 2)}+\Omega\left(R_{\text {min }}\right)_{i,(n / 2)+1}\right) & n \text { odd }\end{cases}
\end{gathered}
$$

where $n$ is the number of observations of the respective benchmark at time $i$, and $i$ is the respective time at which the omega measure is calculated.

We interpret the omega benchmark as the benchmark of the respective strategy group that a hedge fund will need to outperform in order to be ranked 'above average'. In the following equation, we calculate the difference between the omega measure of an individual hedge fund and its benchmark, $\Omega\left(R_{\text {min }}\right)^{B M}$, defined as excess omega $(\varepsilon \Omega)$ :

$$
\varepsilon \Omega\left(R_{\min }\right)_{i, n}=\Omega\left(R_{\min }\right)_{i, n}-\Omega\left(R_{\min }\right)_{i}^{B M}
$$




\section{DATA}

Our empirical work is based on monthly time series of 3,450 individual hedge funds from the Absolute Return database of Hedge Fund Intelligence (the 'HFI database'). We chose this database because it keeps defunct funds to account for survivorship bias (for an overview of the different biases of hedge fund databases please see Fung and Hsieh ${ }^{38}$ or Füss and Kaiser). ${ }^{39}$ It also maintains a complete fee structure (management fee, performance fee, high watermark, and hurdle rate), which is especially relevant for analysing lifecycles.

To ensure our database is homogeneous and not overly influenced by exogenous shocks, we use January 1996 to May 2006 as our sample period. This guarantees that the big hedge fund crisis of 1998 will be included in our results. After clearing the database of extraneous data (eg onshore/offshore versions of the same fund, or different share classes of the same fund), the remaining time series includes descriptive variables for 1,433 hedge funds.

We note that the trading strategies of today's hedge funds are quite varied (for an overview see Füss et al. ${ }^{40}$ ). Similar to the correlation between fixed income and equity indices, we can classify hedge fund strategies into two categories: market directional and nonmarket directional (see Agarwal and $\mathrm{Naik}^{5}$ ). We classify and analyse eight different hedge fund strategies. Table 1 gives the number of target funds in each.

Table 2 shows our database after the clearing and aggregation steps. The average fund in the database has US\$296.46 million assets under management, a track record of five years, and a minimum investment volume of US\$862,670. On the fee side, the average management fee is
1.56 per cent p.a., and the average performance fee is 20 per cent p.a.

\section{RESULTS}

The result tables represent aggregated results based on our calculations for each fund in the database on the basis of monthly performance. To verify Hypotheses $1-3$, we classify the hedge funds in each strategy group into quartile groups according to their excess omegas. We can subsequently calculate the medians for each strategy (group) based on the descriptive variables of individual hedge funds.

Because the start time of each hedge fund may influence its long-term excess omega, we use + (-) to distinguish between funds that start with a positive (negative) excess omega. When investigating the individual phases of a hedge fund lifecycle, we define a phase as a period of four months. This means that we include rolling 12-month excess omegas in our phase analysis, but we ultimately define a phase as a time horizon in which the algebraic sign of the variable does not change for more than three consecutive months in a row. If the algebraic sign changes for a time horizon of at least four months, we have a new phase, beginning with the month of the first change. We define a positive phase as one with an excess omega greater than zero, and vice versa.

Based on our style of analysis, it is important for accuracy that we consider the number of funds in the sample period. Table 3 gives a detailed analysis of the number of hedge funds in the individual strategies. After almost four years (about 45.5 months), there are time series data for less than 50 per cent of the 1,433 individual 
Table 1: Total number of hedge funds in each strategy group

\begin{tabular}{lcc}
\hline & Number of funds & Percentage of database $^{a}$ \\
\hline Directional strategies (DI) & 1,029 & 71.81 \\
Distressed securities (DS) & 36 & 2.51 \\
Global macro (GM) & 254 & 17.73 \\
Long/short equity (LS) & 653 & 45.57 \\
Emerging markets (EM) & 86 & 6.00 \\
Nondirectional strategies (ND) & 404 & 28.19 \\
Convertible arbitrage (CA) & 154 & 10.75 \\
Event driven (ED) & 101 & 7.05 \\
Fixed income arbitrage (FI) & 100 & 6.98 \\
Equity market neutral (MN) & 49 & 3.42 \\
Total strategies (TS) & 1.433 & 100,00
\end{tabular}

${ }^{\mathrm{a}}$ Cleared according to the requirements.

Table 2: Database description

\begin{tabular}{lcrrrr}
\hline & Minimum & Maximum & Std. dev. & Median & Mean \\
\hline Assets under management (USD millions) & 0.21 & $12,700.00$ & 736.01 & 83.50 & 296.46 \\
Fund age (months) & 12.00 & 464.00 & 46.80 & 49.00 & 63.20 \\
Minimum investment (USD thousands) & 0.13 & $64,000.00$ & $2,239.19$ & 500.00 & 862.67 \\
Management fee (p.a.) & $0.25 \%$ & $6.00 \%$ & $0.49 \%$ & $1.50 \%$ & $1.56 \%$ \\
Performance fee & $2.00 \%$ & $50.00 \%$ & $2.61 \%$ & $20.00 \%$ & $20.00 \%$ \\
\hline
\end{tabular}

hedge funds considered in the beginning. For our entire sample period of January 1996 to May 2006 (109 months), only 55 funds, or 3.84 per cent, have a complete time series. Hence the representativity of our results decreases over time, and especially after an observation period of four years. Since our goal here is, however, to describe the lifecycle pattern, our results are not constrained by the decreasing number of funds over time. We assume only a minor distortion of our results due to inherent survivorship bias.

\section{Influence of fund age}

We find that Hypothesis 1, that risk-adjusted returns of individual hedge funds decrease over time, is confirmed when considering the development of the omega measure. We can see this development in Figures 1-3, and even more clearly when the graphic representation of the omega development is enhanced by a thirddegree polynomial trend line. ${ }^{41}$ Here, the lifecycles are presented only as long as the sample consists of at least 50 per cent of the target funds. 
Table 3: Development of the number of funds in the database

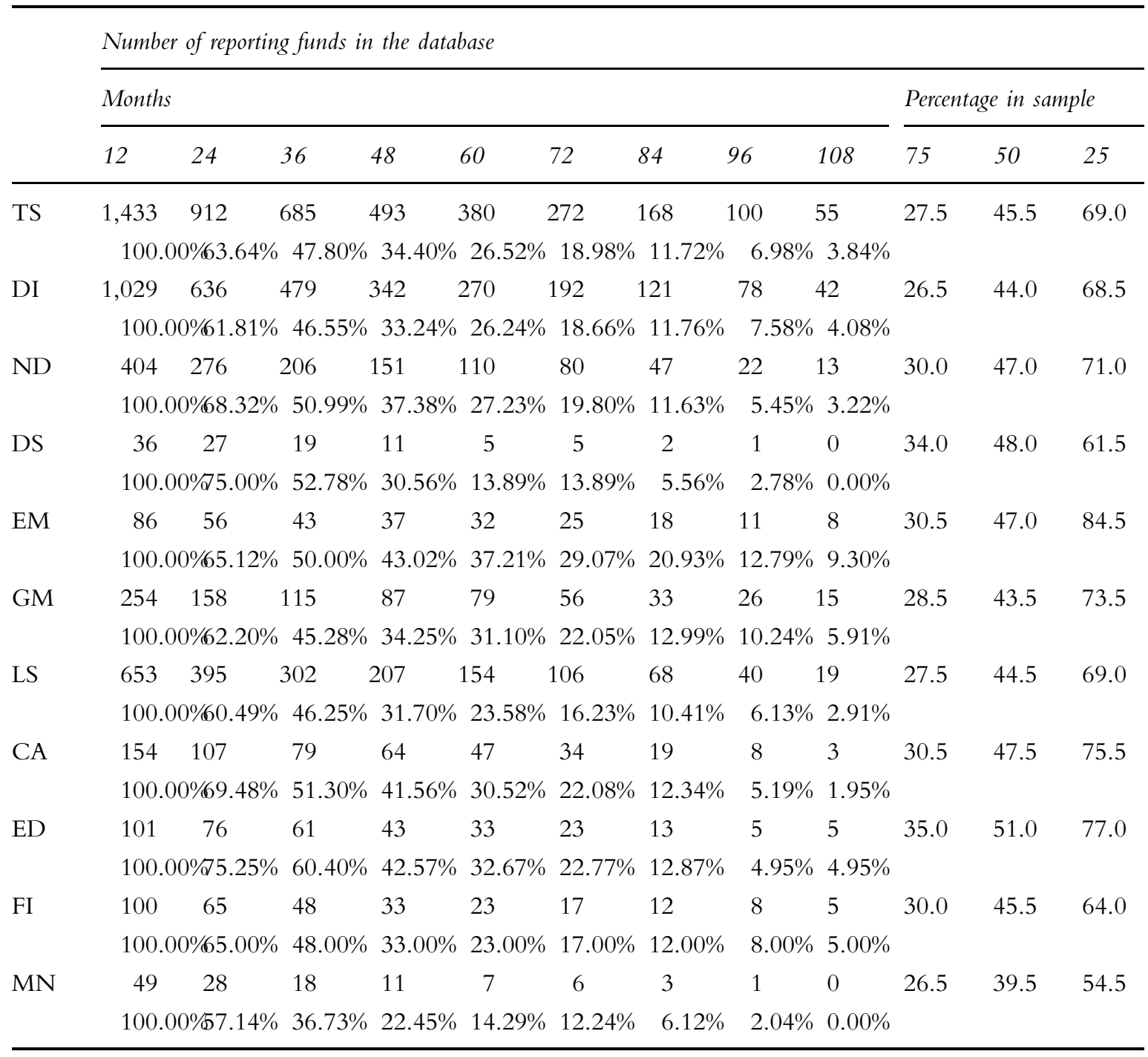

Note from Figure 1 that, on an aggregated level, hedge funds show above-average omega measures, especially in their first two years. After this, the omega measure may stay at a constant level of about 1.90 for the rest of our sample period.

As Figure 2 shows, we can detect no distinct lifecycle for the directional strategies on average. The 12-month rolling omegas alternate between 2.25 in the beginning, and a minimum of 1.90. As Figure 3 shows, nondirectional strategies show a distinct lifecycle. The omega measure decreases over the first three years from 3.40 to 2.10 . Hence our second hypothesis, that risk-adjusted returns of nondirectional hedge fund strategies 


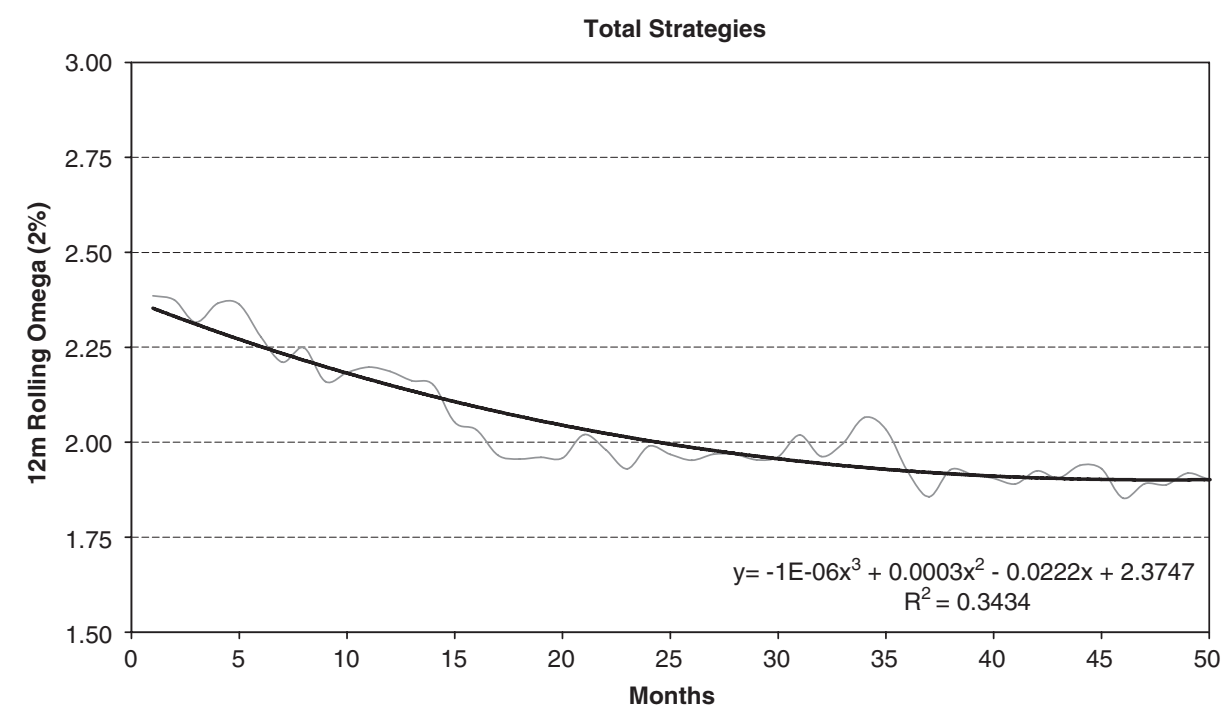

Figure 1: Twelve-month rolling omegas for the entire database

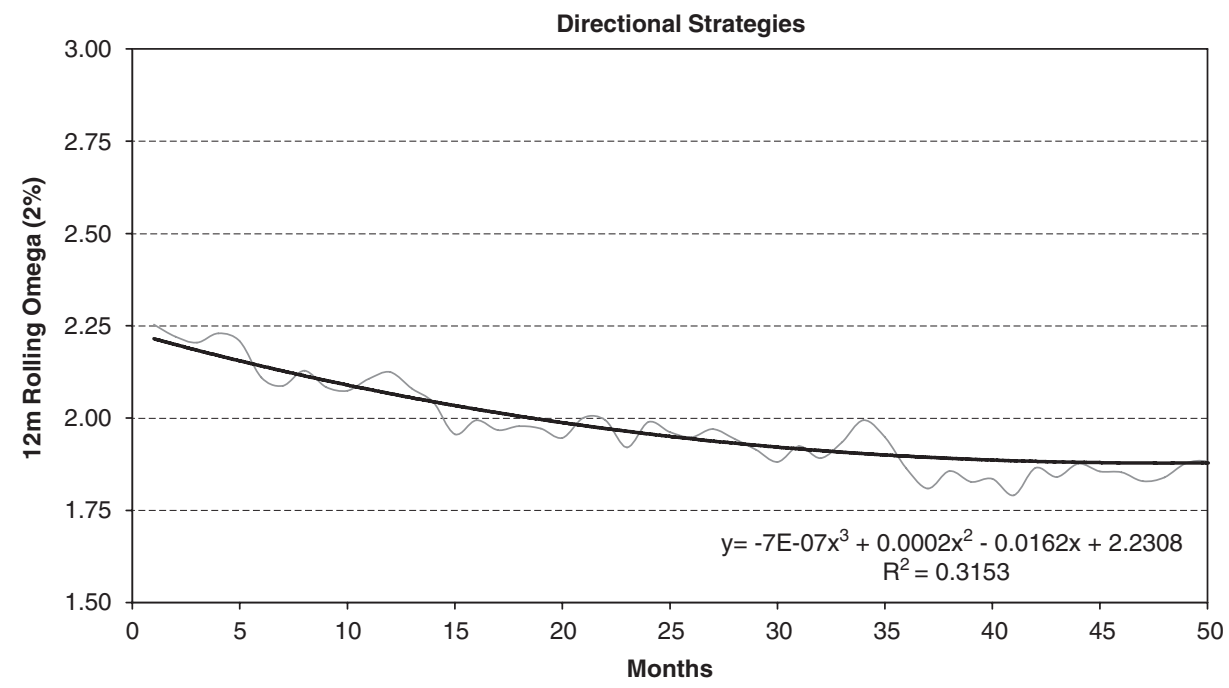

Figure 2: Twelve-month rolling omegas for directional strategies

erode more quickly than those of directional strategies, is confirmed.

\section{Influence of the phase}

In the phase analysis, we investigate the difference between the omega measure and the benchmark omega based on the median of the individual hedge fund omega. Again, note that we consider a new phase has occurred if we note a change in phase (eg from negative to positive, or vice versa) for at least four consecutive months. 


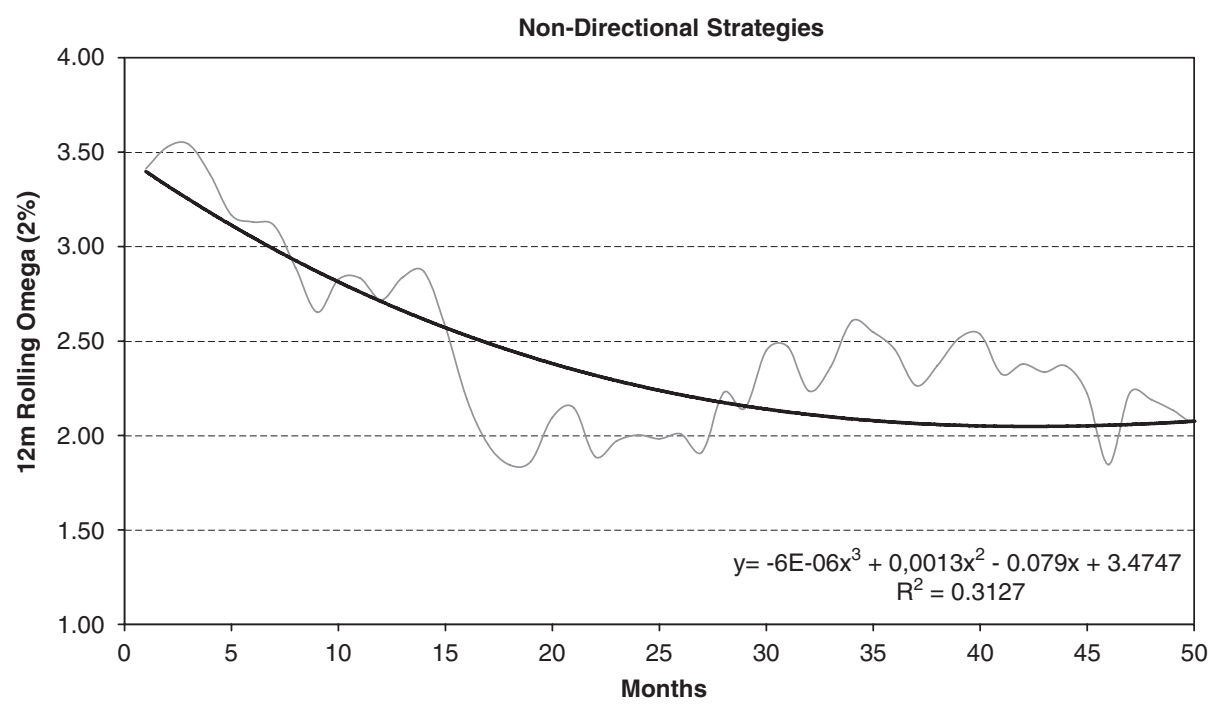

Figure 3: Twelve-month rolling omegas for nondirectional strategies

Within the directional strategies, we note a slight difference in the median number of months (see Table 4). For funds with a positive start, the difference is 42 ; for those with a negative start, it is 45.5 . The median number of phases is, however, smaller for funds with a positive start (2) than for those with a negative start (3). Also, the median excess omega for above-averagestarting directional hedge funds is 0.74 , which is distinctly higher than for funds with a negative start $(-0.31)$.

The percentage of positive excess omegas for directional funds with a positive start (65 per cent) is also above the percentage of funds with a negative start (44.17 per cent). Further discrepancies can be observed regarding maximum values, average values for positive excess omegas, and standard deviations.

We next consider individual quartiles. Along with the median and maximum value, the percentage of positive excess omegas of directional hedge funds is highest in the first quartile and lowest in the fourth quartile.
Furthermore, note that directional hedge funds with a positive start phase in the first quartile in their median go through only one phase. We can interpret this as follows: The directional hedge funds of the first quartile go through fewer phases compared with less successful funds over the long run. Hence, they generate excess omegas more reliably.

In addition to the global context of all strategies, the minimum and maximum number of phases for directional strategies are one and 10 (see Table 5). As we have noted already for all funds, the number of funds with directional strategies in the first phase with a positive start is higher than for those with a negative start. This ratio, however, changes during the second, third, and second to last phase, in which more negative than positive funds report to the database provider.

In fact, the number of reporting funds with a positive start phase is more than halved until the third phase. For those with a negative start, it lasts until the fourth phase. More than 
Table 4: Excess omegas of directional strategies

\begin{tabular}{|c|c|c|c|c|c|c|c|c|c|c|c|}
\hline & & \multirow{2}{*}{$\begin{array}{l}\text { Number of } \\
\text { funds }\end{array}$} & \multirow{2}{*}{$\begin{array}{l}\text { Number of } \\
\text { months } \\
(\mathrm{Med})\end{array}$} & \multirow{2}{*}{$\begin{array}{l}\text { Number of } \\
\text { phases } \\
\text { (Med) }\end{array}$} & \multicolumn{7}{|l|}{$\varepsilon \Omega$} \\
\hline & & & & & Med & $\begin{array}{l}\text { Fraction } \\
\text { positive } \\
(\%)\end{array}$ & $\begin{array}{l}\varnothing \\
\text { positive }\end{array}$ & $\begin{array}{l}\varnothing \\
\text { negative }\end{array}$ & Min & $\operatorname{Max}$ & $\begin{array}{l}\text { Std. } \\
d e v .\end{array}$ \\
\hline \multirow[t]{5}{*}{+} & Total & 529 & 42.0 & 2 & 0.74 & 65.00 & 6.18 & -0.86 & -1.96 & 50.00 & 8.31 \\
\hline & Q1 & 132 & 32.5 & 1 & 6.27 & 90.69 & 18.08 & -0.91 & -1.94 & 50.00 & 17.22 \\
\hline & Q2 & 133 & 35.0 & 2 & 1.33 & 73.91 & 4.72 & -0.83 & -2.00 & 47.58 & 6.82 \\
\hline & Q3 & 132 & 47.5 & 3 & 0.33 & 58.34 & 3.81 & -0.76 & -1.91 & 19.55 & 4.51 \\
\hline & Q4 & 132 & 53.5 & 4 & -0.33 & 39.84 & 3.78 & -0.97 & -2.00 & 17.31 & 3.99 \\
\hline \multirow[t]{5}{*}{-} & Total & 500 & 45.5 & 3 & -0.31 & 44.17 & 3.56 & -0.95 & -2.02 & 16.74 & 3.49 \\
\hline & Q1 & 125 & 52.0 & 2 & 0.97 & 68.66 & 6.61 & -0.83 & -1.94 & 50.00 & 10.49 \\
\hline & Q2 & 125 & 50.0 & 3 & -0.02 & 51.28 & 2.95 & -0.81 & -1.92 & 16.70 & 3.45 \\
\hline & Q3 & 125 & 46.0 & 3 & -0.53 & 35.14 & 2.14 & -0.88 & -1.97 & 6.74 & 1.81 \\
\hline & Q4 & 125 & 33.0 & 1 & -1.12 & 15.91 & 2.45 & -1.28 & -2.08 & 6.09 & 1.62 \\
\hline \multicolumn{2}{|c|}{ Total } & 1.029 & 44.0 & 3 & 0.18 & 54.55 & 4.91 & -0.90 & -1.98 & 31.52 & 6.01 \\
\hline
\end{tabular}

Min=Minimum, Max=Maximum, Std. dev. $=$ Standard deviation, Med=Median .

68 per cent of the funds with a positive start in the first quartile cease reporting after phase 1; the number of below-average-starting funds in the last quartile decreases by almost 54 per cent after phase 1.

For nondirectional strategies, we observe a difference in the median number of months (see Table 6). For funds with a positive start, the number is 49.0 ; for those with a negative start, it is 42.5 . The median number of phases for funds with a positive start (3) also decreases more quickly than it does for those with a belowaverage start (2). Furthermore, the median excess omegas for above-average-starting nondirectional hedge funds is 1.69 , distinctly higher than for those with a negative start $(-0.50)$. Hence more nondirectional hedge funds yield above-average results than those yielding below-average excess omegas. The percentage of positive excess omegas for nondirectional funds with a positive start (69.50 per cent) is higher than for those with a negative start (40.0 per cent).

We also note differences in the standard deviations and in the average values of positive excess omegas between nondirectional hedge funds with positive and negative starts. No further discrepancies are observed regarding the minimum and maximum or the average values for negative excess omegas.

When considering individual quartiles, we find that the percentage of positive excess omegas for nondirectional hedge funds is highest in the first quartile and lowest in the fourth quartile. Note 
Table 5: Phase analysis of directional strategies

\begin{tabular}{|c|c|c|c|c|c|c|c|c|c|c|c|c|c|c|c|c|c|c|}
\hline \multirow[t]{2}{*}{$P$} & \multicolumn{2}{|c|}{ Number of funds } & \multicolumn{3}{|c|}{ Length (in months) } & \multicolumn{4}{|l|}{$\varepsilon \Omega$} & \multicolumn{2}{|c|}{ Number of funds } & \multicolumn{3}{|c|}{ Length (in months) } & \multicolumn{4}{|l|}{$\varepsilon \Omega$} \\
\hline & $a b s$ & kum (\%) & Med & Min & $\operatorname{Max}$ & Std. dev. & Med & Min & $\operatorname{Max}$ & $a b s$ & kum (\%) & Med & Min & $\operatorname{Max}$ & Std. dev & Med & Min & $\operatorname{Max}$ \\
\hline & 1 & & & & & & & & & 2 & & & & & & & & \\
\hline+ To & 529 & 100 & 16 & 4 & 89 & 3.71 & 2.35 & -0.17 & 14.14 & 383 & 72 & 12 & 1 & 62 & 0.51 & -0.90 & -1.59 & -0.06 \\
\hline Q1 & 132 & 100 & 25 & 4 & 89 & 17.17 & 8.39 & -0.18 & 50.00 & 41 & 31 & 8 & 0 & 45 & 0.73 & -0.92 & -1.79 & -0.03 \\
\hline Q2 & 133 & 100 & 19 & 4 & 63 & 3.83 & 1.88 & -0.33 & 15.23 & 90 & 68 & 7 & 0 & 33 & 0.50 & -1.01 & -1.69 & -0.15 \\
\hline Q3 & 132 & 100 & 13 & 4 & 53 & 2.19 & 1.16 & -0.31 & 6.81 & 120 & 91 & 12 & 4 & 39 & 0.43 & -0.69 & -1.35 & -0.03 \\
\hline Q4 & 132 & 100 & 9 & 4 & 37 & 1.78 & 1.48 & 0.03 & 5.36 & 132 & 100 & 19 & 4 & 62 & 0.54 & -0.97 & -1.75 & -0.03 \\
\hline - To & 500 & 100 & 15 & 4 & 82 & 0.61 & -1.01 & -1.78 & 0.14 & 408 & 82 & 13 & 0 & 61 & 2.51 & 1.50 & 0.01 & 8.78 \\
\hline Q1 & 125 & 100 & 9 & 4 & 30 & 0.53 & -1.04 & -1.62 & -0.08 & 125 & 100 & 21 & 4 & 61 & 8.47 & 1.93 & -0.24 & 30.64 \\
\hline Q2 & 125 & 100 & 12 & 4 & 44 & 0.64 & -0.76 & -1.58 & 0.20 & 122 & 98 & 14 & 4 & 56 & 2.15 & 1.32 & 0.00 & 8.06 \\
\hline Q3 & 125 & 100 & 17 & 4 & 73 & 0.60 & -0.84 & -1.78 & 0.21 & 103 & 82 & 11 & 0 & 34 & 1.53 & 1.28 & 0.05 & 4.98 \\
\hline Q4 & 125 & 100 & 24 & 5 & 82 & 0.65 & -1.28 & -2.02 & 0.50 & 58 & 46 & 10 & 4 & 34 & 2.10 & 1.47 & 0.13 & 6.72 \\
\hline To & 1029 & 100 & 15 & 4 & 89 & 1.09 & 0.20 & -1.25 & 2.84 & 791 & 77 & 13 & 0 & 62 & 0.85 & 0.28 & -0.96 & 1.69 \\
\hline & 3 & & & & & & & & & 4 & & & & & & & & \\
\hline+ To & 256 & 48 & 14 & 4 & 71 & 6.33 & 2.11 & 0.00 & 21.10 & 164 & 31 & 12 & 4 & 49 & 0.48 & -0.83 & -1.62 & -0.08 \\
\hline Q1 & 27 & 20 & 21 & 4 & 57 & 16.97 & 42.36 & 1.30 & 50.00 & 7 & 5 & 7 & 4 & 14 & 0.91 & -1.23 & -2.63 & -0.22 \\
\hline Q2 & 51 & 38 & 17 & 8 & 71 & 18.23 & 7.90 & 0.44 & 50.00 & 30 & 23 & 10 & 4 & 29 & 0.41 & -0.69 & -1.41 & -0.17 \\
\hline Q3 & 96 & 73 & 16 & 4 & 45 & 11.65 & 2.74 & 0.04 & 50.00 & 60 & 45 & 11 & 4 & 31 & 0.48 & -0.85 & -1.71 & -0.07 \\
\hline Q4 & 82 & 62 & 12 & 4 & 40 & 4.07 & 1.54 & -0.09 & 13.55 & 67 & 51 & 15 & 4 & 49 & 0.50 & -0.88 & -1.58 & -0.03 \\
\hline - To & 272 & 54 & 12 & 0 & 67 & 0.59 & -0.69 & -1.37 & 0.03 & 144 & 29 & 13 & 4 & 73 & 2.04 & 1.30 & 0.01 & 6.42 \\
\hline Q1 & 59 & 47 & 7 & 0 & 67 & 1.61 & 1.13 & 0.00 & 5.21 & 37 & 30 & 22 & 5 & 73 & 4.33 & 1.99 & 0.01 & 16.71 \\
\hline Q2 & 88 & 70 & 12 & 4 & 48 & 0.48 & -0.77 & -1.39 & -0.05 & 59 & 47 & 13 & 4 & 39 & 1.48 & 1.18 & 0.00 & 4.63 \\
\hline Q3 & 84 & 67 & 13 & 0 & 67 & 0.51 & -0.83 & -1.53 & -0.04 & 40 & 32 & 11 & 4 & 30 & 1.58 & 0.79 & 0.09 & 4.48 \\
\hline Q4 & 41 & 33 & 16 & 4 & 55 & 0.66 & -1.38 & -1.97 & -0.01 & 8 & 6 & 12 & 4 & 15 & 4.10 & 1.61 & -0.01 & 12.22 \\
\hline To & 528 & 51 & 13 & 0 & 71 & 0.83 & -0.14 & -1.05 & 1.65 & 308 & 30 & 12 & 4 & 73 & 0.71 & -0.30 & -1.17 & 0.97 \\
\hline
\end{tabular}




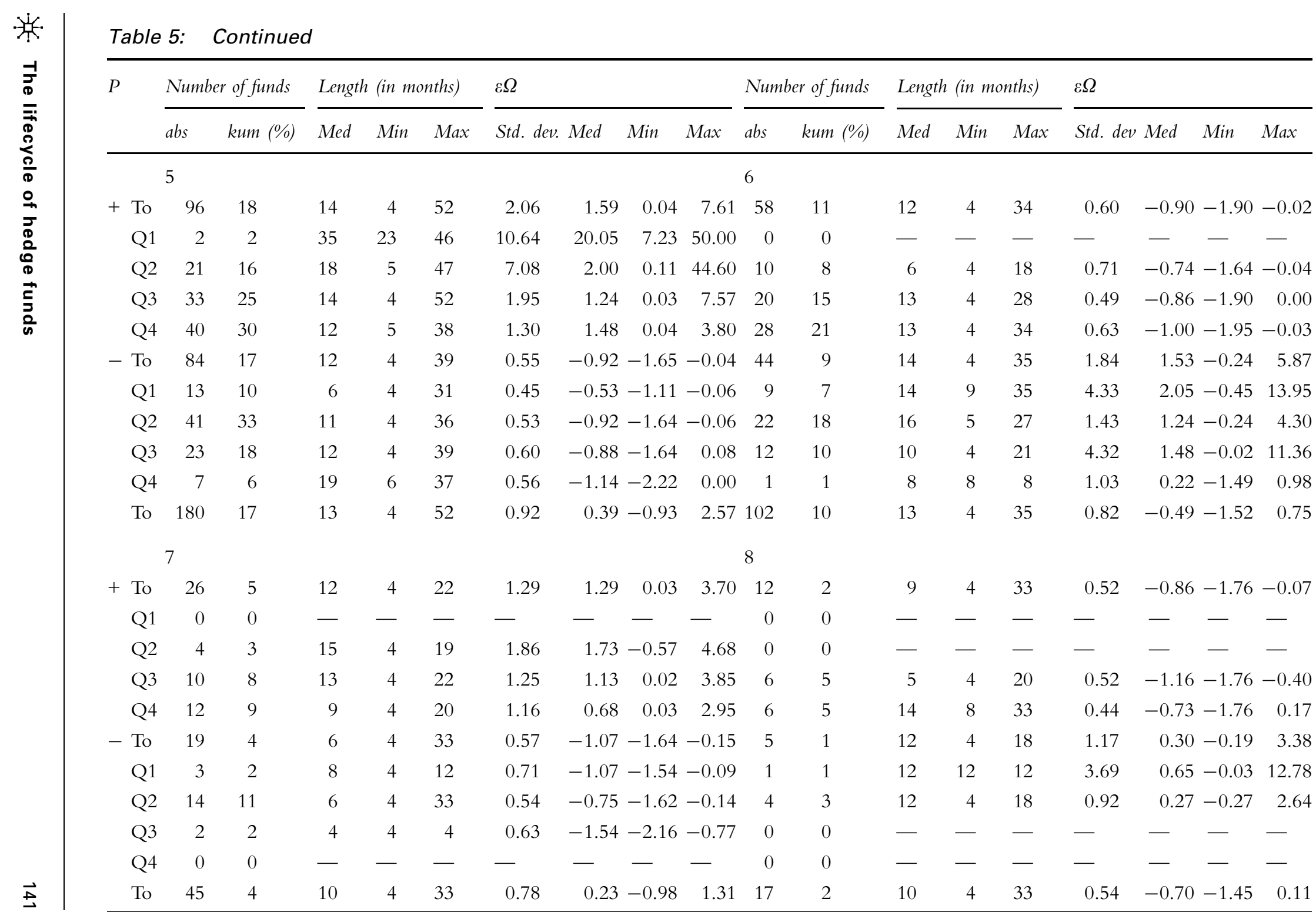


Table 5: Continued

\begin{tabular}{|c|c|c|c|c|c|c|c|c|c|c|c|c|c|c|c|c|c|c|}
\hline \multirow[t]{2}{*}{$P$} & \multicolumn{2}{|c|}{ Number of funds } & \multicolumn{3}{|c|}{ Length (in months) } & \multicolumn{4}{|l|}{$\varepsilon \Omega$} & \multicolumn{2}{|c|}{ Number of funds } & \multicolumn{3}{|c|}{ Length (in months) } & \multicolumn{4}{|l|}{$\varepsilon \Omega$} \\
\hline & $a b s$ & kum (\%) & Med & Min & $\operatorname{Max}$ & Std. dev. & Med & Min & $\operatorname{Max}$ & $a b s$ & kum (\%) & Med & Min & $\operatorname{Max}$ & Std. dev & Med & Min & $\operatorname{Max}$ \\
\hline & 9 & & & & & & & & & 10 & & & & & & & & \\
\hline+ To & 2 & 0 & 6 & 5 & 6 & 0.31 & 0.45 & 0.13 & 0.96 & 1 & 0 & 6 & 6 & 6 & 0.47 & -0.86 & -1.82 & -0.46 \\
\hline Q1 & 0 & 0 & - & - & - & - & - & - & - & 0 & 0 & - & - & - & - & - & - & - \\
\hline Q2 & 0 & 0 & - & - & - & - & - & - & - & 0 & 0 & - & - & - & - & - & - & - \\
\hline Q3 & 1 & 1 & 5 & 5 & 5 & 0.08 & 0.12 & 0.11 & 0.30 & 1 & 1 & 6 & 6 & 6 & 0.47 & -0.86 & -1.82 & -0.46 \\
\hline Q4 & 1 & 1 & 6 & 6 & 6 & 0.53 & 0.78 & 0.14 & 1.61 & 0 & 0 & - & - & - & - & - & - & - \\
\hline- To & 3 & 1 & 5 & 5 & 6 & 0.69 & -1.27 & -1.75 & 0.00 & 0 & 0 & - & - & - & - & - & - & - \\
\hline Q1 & 1 & 1 & 6 & 6 & 6 & 0.85 & -1.27 & -2.35 & 0.00 & 0 & 0 & - & - & - & - & - & - & - \\
\hline Q2 & 2 & 2 & 5 & 5 & 5 & 0.50 & -1.22 & -1.67 & -0.44 & 0 & 0 & - & - & - & - & - & - & - \\
\hline Q3 & 0 & 0 & - & - & - & - & - & - & - & 0 & 0 & - & - & - & - & - & - & - \\
\hline Q4 & 0 & 0 & - & - & - & - & - & - & - & 0 & 0 & - & - & - & - & - & - & - \\
\hline To & 5 & 0 & 5 & 5 & 6 & 0.53 & -0.97 & -1.60 & 0.00 & 1 & 0 & 6 & 6 & 6 & 0.47 & -0.86 & -1.82 & -0.46 \\
\hline
\end{tabular}

$\mathrm{P}=$ Phase, Min=Minimum, Max=Maximum, Std. dev. $=$ Standard deviation, Med=Median, abs=absolute, kum=cumulative. 
Table 6: Excess omegas for nondirectional strategies

\begin{tabular}{|c|c|c|c|c|c|c|c|c|c|c|c|}
\hline & & & Number of & Number of & $\varepsilon \Omega$ & & & & & & \\
\hline & & of funds & $\begin{array}{l}\text { months } \\
\text { (Med) }\end{array}$ & $\begin{array}{l}\text { phases } \\
(\mathrm{Med})\end{array}$ & Med & $\begin{array}{l}\text { Fraction } \\
\text { positive (\%) }\end{array}$ & $\begin{array}{l}\varnothing \\
\text { positive }\end{array}$ & $\begin{array}{l}\varnothing \\
\text { negative }\end{array}$ & Min & Max & Std. dev. \\
\hline \multirow[t]{5}{*}{+} & Total & 222 & 49.0 & 3 & 1.69 & 69.50 & 15.42 & -1.12 & -2.06 & 50.00 & 13.86 \\
\hline & Q1 & 55 & 45.0 & 1 & 50.00 & 100.00 & 36.81 & -0.96 & 2.10 & 50.00 & 17.28 \\
\hline & $\mathrm{Q} 2$ & 56 & 47.0 & 3 & 3.65 & 76.17 & 15.42 & -1.00 & -2.01 & 50.00 & 17.91 \\
\hline & Q3 & 56 & 54.0 & 3 & 0.75 & 61.39 & 7.63 & -1.09 & -2.22 & 50.00 & 10.92 \\
\hline & Q4 & 55 & 53.0 & 3 & -0.52 & 39.34 & 10.35 & -1.21 & -2.49 & 50.00 & 11.49 \\
\hline \multirow[t]{5}{*}{-} & Total & 182 & 42.5 & 2 & -0.50 & 40.00 & 8.36 & -1.41 & -2.78 & 50.00 & 8.68 \\
\hline & Q1 & 45 & 53.0 & 2 & 1.98 & 68.97 & 15.66 & -1.30 & -2.78 & 50.00 & 16.96 \\
\hline & Q2 & 46 & 53.0 & 3 & -0.17 & 46.79 & 5.61 & -1.27 & -2.62 & 50.00 & 7.66 \\
\hline & Q3 & 46 & 44.0 & 3 & -0.84 & 26.64 & 3.16 & -1.20 & -2.73 & 13.63 & 3.08 \\
\hline & Q4 & 45 & 26.0 & 1 & -1.72 & 14.29 & 7.18 & -1.84 & -3.08 & 7.58 & 2.31 \\
\hline Total & & 404 & 46.5 & 3 & 0.32 & 55.50 & 12.02 & -1.26 & -2.42 & 50.00 & 11.89 \\
\hline
\end{tabular}

Min= Minimum, Max=Maximum, Std. dev. $=$ Standard deviation, Med $=$ Median .

further that nondirectional hedge funds with a positive start phase in the first quartile in their median go through only one phase.

We can thus hypothesise as follows:

Nondirectional hedge funds in the first quartile go through fewer phases compared with less successful funds over the long run. Hence they generate excess omegas more reliably. Funds in the fourth quartile with a negative start, however, also have a median number of phases of just one. We conclude that, over the long run, less successful hedge funds go through fewer phases.

In contrast to directional strategies, the minimum and maximum number of phases for nondirectional strategies are lower, at one and eight, respectively (see Table 7). Funds with these strategies, however, show huge differences in phase length, ranging from 4 to 109 months. The number of funds with a positive start in the first phase is higher than the number with a negative start.

This ratio begins to change in phase 4 , however. The number of reporting funds with a positive start phase is more than halved until the fourth phase, while the number of those with a negative start is halved until the third phase.

Also, for nondirectional strategies, the number of reporting funds decreases in the first and last quartiles. More than 78 per cent of funds with a positive start in the first quartile cease reporting after phase 1; the number of below-average starting funds in the last quartile decreases by almost 60 per cent after phase 1 . 
Table 7: Phase analysis of nondirectional strategies

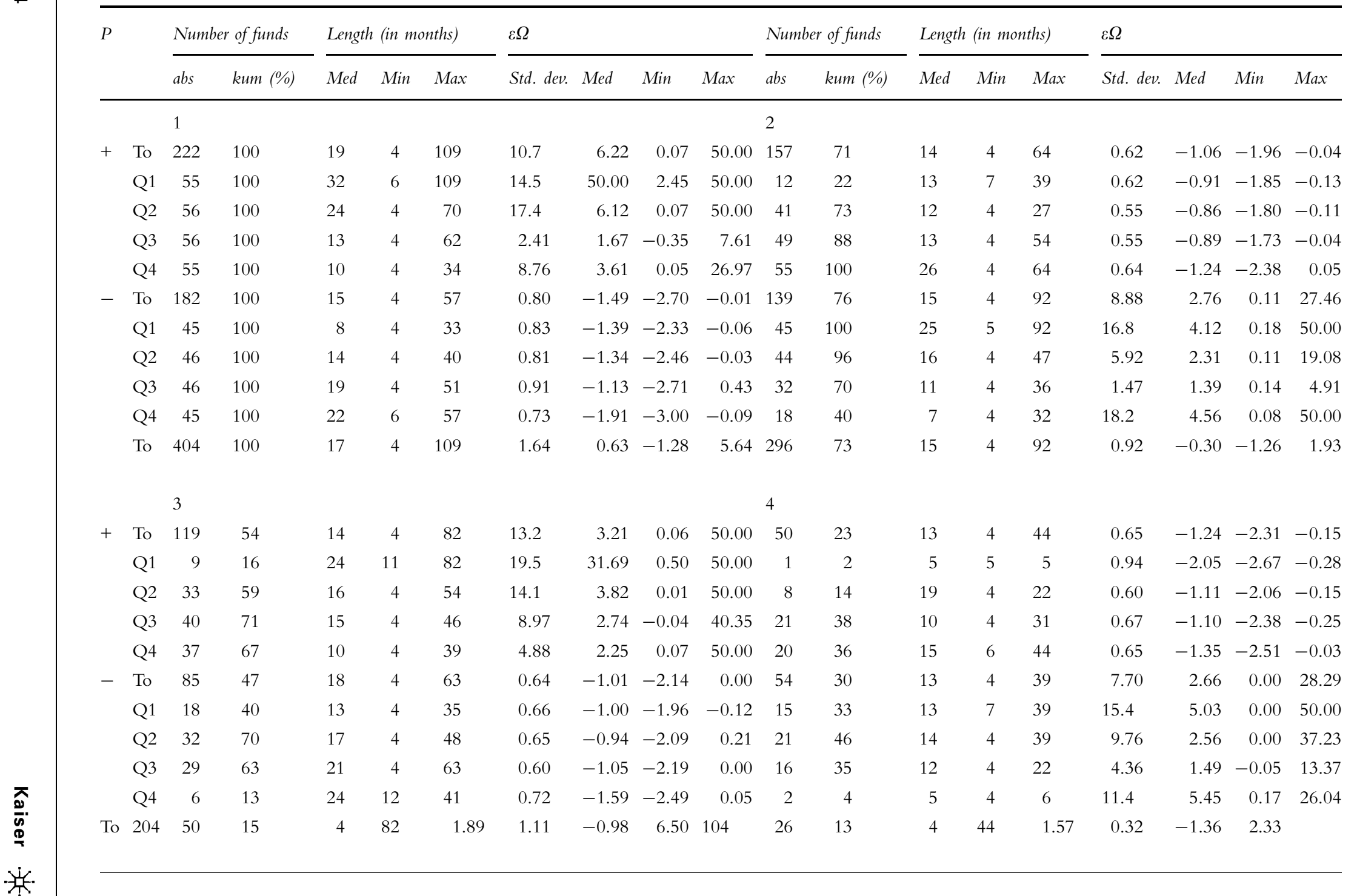




\begin{tabular}{|c|c|c|c|c|c|c|c|c|c|c|c|c|c|c|c|c|c|c|c|}
\hline \multirow{2}{*}{\multicolumn{2}{|c|}{$P$}} & \multicolumn{2}{|c|}{ Number of funds } & \multicolumn{3}{|c|}{ Length (in months) } & \multicolumn{4}{|l|}{$\varepsilon \Omega$} & \multicolumn{2}{|c|}{ Number of funds } & \multicolumn{3}{|c|}{ Length (in months) } & \multicolumn{4}{|l|}{$\varepsilon \Omega$} \\
\hline & & $a b s$ & kum (\%) & Med & $\operatorname{Min}$ & $\operatorname{Max}$ & Std. dev. & Med & Min & $\operatorname{Max}$ & $a b s$ & kum (\%) & Med & Min & $\operatorname{Max}$ & Std. dev. & Med & Min & $\operatorname{Max}$ \\
\hline & & 5 & & & & & & & & & 6 & & & & & & & & \\
\hline \multirow[t]{5}{*}{+} & To & 28 & 13 & 14 & 4 & 44 & 17.1 & 4.92 & 0.10 & 50.00 & 11 & 5 & 15 & 6 & 33 & 0.49 & -1.05 & -2.26 & 0.00 \\
\hline & Q1 & 0 & 0 & - & - & - & - & - & - & - & 0 & 0 & - & - & - & - & - & - & - \\
\hline & Q2 & 7 & 13 & 14 & 8 & 44 & 20.1 & 9.70 & 0.00 & 50.00 & 1 & 2 & 6 & 6 & 6 & 0.32 & -1.05 & -1.21 & -0.33 \\
\hline & Q3 & 12 & 21 & 15 & 4 & 34 & 17.1 & 7.75 & 0.24 & 50.00 & 3 & 5 & 12 & 12 & 26 & 0.48 & -1.14 & -1.99 & -0.34 \\
\hline & Q4 & 9 & 16 & 10 & 5 & 20 & 6.39 & 2.00 & 0.10 & 20.58 & 7 & 13 & 18 & 8 & 33 & 0.79 & -0.92 & -2.48 & 0.10 \\
\hline \multirow[t]{7}{*}{-} & To & 22 & 12 & 11 & 4 & 44 & 0.55 & -1.14 & -1.92 & -0.03 & 14 & 8 & 11 & 5 & 29 & 3.70 & 2.71 & 0.11 & 13.31 \\
\hline & Q1 & 5 & 11 & 9 & 4 & 11 & 0.46 & -0.61 & -1.22 & 0.00 & 5 & 11 & 22 & 6 & 29 & 16.6 & 2.96 & 0.20 & 50.00 \\
\hline & Q2 & 10 & 22 & 8 & 4 & 19 & 0.66 & -1.14 & -1.99 & -0.08 & 4 & 9 & 10 & 5 & 22 & 6.59 & 2.24 & -0.79 & 21.54 \\
\hline & Q3 & 6 & 13 & 13 & 5 & 25 & 0.55 & -1.56 & -2.23 & -0.19 & 5 & 11 & 7 & 6 & 15 & 2.81 & 2.41 & 0.12 & 8.16 \\
\hline & Q4 & 1 & 2 & 44 & 44 & 44 & 0.79 & -1.78 & -3.80 & -0.69 & 0 & 0 & - & - & - & - & - & - & - \\
\hline & To & 50 & 12 & 13 & 4 & 44 & 2.08 & 0.64 & -1.01 & 7.91 & 25 & 6 & 14 & 5 & 33 & 2.66 & 1.06 & -1.42 & 6.43 \\
\hline & & 7 & & & & & & & & & 8 & & & & & & & & \\
\hline \multirow[t]{5}{*}{+} & To & 5 & 2 & 20 & 8 & 28 & 16.5 & 2.35 & -0.24 & 50.00 & 0 & 0 & - & - & - & - & - & - & - \\
\hline & Q1 & 0 & 0 & - & - & - & - & - & - & - & 0 & 0 & - & - & - & - & - & - & - \\
\hline & Q2 & 1 & 2 & 28 & 28 & 28 & 22.9 & 2.35 & -0.35 & 50.00 & 0 & 0 & - & - & - & - & - & - & - \\
\hline & Q3 & 2 & 4 & 16 & 12 & 20 & 9.61 & 12.56 & 2.94 & 28.14 & 0 & 0 & - & - & - & - & - & - & - \\
\hline & Q4 & 2 & 4 & 15 & 8 & 22 & 12.5 & 2.69 & -0.18 & 28.46 & 0 & 0 & - & - & - & - & - & - & - \\
\hline \multirow[t]{6}{*}{-} & Тo & 5 & 3 & 17 & 5 & 26 & 0.83 & -1.26 & -3.14 & -0.16 & 1 & 1 & 13 & 13 & 13 & 19.3 & 4.99 & -3.93 & 50.00 \\
\hline & Q1 & 1 & 2 & 12 & 12 & 12 & 1.18 & -1.11 & -3.90 & -0.09 & 1 & 2 & 13 & 13 & 13 & 19.3 & 4.99 & -3.93 & 50.00 \\
\hline & Q2 & 1 & 2 & 17 & 17 & 17 & 0.83 & -2.11 & -3.14 & -0.16 & 0 & 0 & - & - & - & - & - & - & - \\
\hline & Q3 & 3 & 7 & 19 & 5 & 26 & 0.74 & -1.26 & -2.44 & -0.67 & 0 & 0 & - & - & - & - & - & - & - \\
\hline & Q4 & 0 & 0 & - & - & - & - & - & - & - & 0 & 0 & - & - & - & - & - & - & - \\
\hline & To & 10 & 2 & 18 & 5 & 28 & 2.45 & 0.19 & -2.03 & 6.60 & 1 & 0 & 13 & 13 & 13 & 19.3 & 4.99 & -3.93 & 50.00 \\
\hline
\end{tabular}


Table 8: $t$-Test results for number of phases and fund age variables

\begin{tabular}{llc}
\hline Database & Mean & \\
\hline & Number of phases & Fund age (months) \\
\hline Directional strategies & 2.96 & 49.67 \\
Nondirectional strategies & 2.71 & 51.62 \\
Difference & $0.26^{\star \star \star}$ & -1.95 \\
\hline
\end{tabular}

$\star \star \star$ denotes significance at the 0.1 level.

We use Student's $t$-test to check whether two samples are taken from the same database. The $t$-test is used to determine whether the difference between two normally distributed groups is statistically significant. We calculate the $t$-test as follows:

$$
t=\frac{\overline{X_{1}}-\overline{X_{2}}}{\sigma}
$$

where $\bar{X}_{1}$ is the mean of sample $1, \bar{X}_{2}$ the mean of sample 2 , and $\sigma$ is the standard deviation of the database.

We consider directional and nondirectional hedge funds in the database. The number of phases and fund age are included for both classes, and we examine for statistically significant differences in Table 8. For the entire database, we observe more growth and contraction phases for directional than for nondirectional phases, thus confirming Hypothesis 3. The difference between both strategies is statistically significant. Fund age for nondirectional strategies is, however, slightly higher than it is for directional strategies, but it is not statistically significant.

\section{CONCLUSIONS}

Hedge funds using strategies that take advantage of market inefficiencies are in danger of delivering only short-term excess returns in competitive markets. We postulate that the lifecycle of hedge funds is such that initial excess returns are likely to fade over time. Funds may subsequently produce nonattractive returns, or even cease to operate without the influx of new investment ideas.

Our goal here is to verify the lifecycle hypothesis for hedge funds. The database we use for this purpose encompasses performance data for 1,433 hedge funds.

We first rigorously adjusted our database, and contrary to many other empirical analyses of hedge fund time series, we chose an approach where every hedge fund is analysed independently from fixed points in time to verify a lifecycle. $^{42}$

The first hypothesis of our hedge fund lifecycle model stated that risk-adjusted returns of individual hedge funds decrease over time. This can be verified with a high degree of significance by means of the omega measure, as well as by the directional and nondirectional strategy groups.

For the total and directional strategy groups, the lifecycle is as follows: During the first three years, the median of the realised omega measures gradually decreases, and then remains at that level. For nondirectional strategies, the lifecycle is especially evident: During the first three years, 
we observe considerably higher omegas than for directional strategies. The omegas, however, decrease here over time as well.

The lifecycle of an average hedge fund can be separated into (1) a phase of high initial success (excess returns) and (2) a contraction phase. This further development is not uniform: Many hedge funds cease operation; others continue to operate on a lower success level; a minority manages to develop new ideas and again collect excess returns. Hypothesis 2, stating that riskadjusted returns of nondirectional hedge fund strategies erode more quickly than those of directional ones, is also confirmed.

Hypothesis 3, stating that hedge funds following directional strategies go through more growth and contraction phases than nondirectional ones, is confirmed as well. The number of phases for nondirectional strategies lies between one and eight for a ten-year time period (the median is three for funds with a positive start, and two for funds with a negative start). For directional strategies, the number of phases lies between one and ten (the median is two for funds with a positive start, and three for funds with a negative start).

With directional as well as nondirectional strategies, the number of hedge funds with a positive start is higher than the number of funds with a negative start. Fifty per cent of directional and nondirectional hedge funds pass through only three phases. The number of reporting funds decreases in the first and last quartile for both directional and nondirectional strategies. Over 68 (78) per cent of nondirectional (directional) hedge funds with a positive start phase in the first quartile remain at the end of the sample period, which we interpret as performance persistence. At the same time, however, the number of nondirectional (directional) hedge funds with a negative start in the last quartile decreases by more than 60 (54) per cent in the first phase. Thus we conclude that nondirectional hedge funds with a negative start cease operations relatively quickly. The results of Hypothesis 3 are statistically significant according to the $t$-test.

The implications of this paper are extensive, as we list below. Hedge funds undergo different phases depending on their individual fund age. This conclusion is not obvious when simply considering hedge fund indices.

(1) Our results imply that a classic 'buy-andhold' strategy leads to distinctly diverging results when the lifecycle of a hedge fund is not considered. In this context, the goal of a future study could be to identify optimal investment strategies for hedge fund portfolio management that include the hedge fund lifecycle.

(2) Furthermore, if we consider that the life of a hedge fund is determined by its phases, we may need to reconsider the overall quality of the established benchmarks in the hedge fund industry. Depending on the exit assumptions in the index concept, the return on investment for a single hedge fund can differ dramatically from the return on investment in index products. Hence we must consider previous results based solely on index data with special caution. In this context, a future study could investigate whether it would be wise to establish lifecycle-dependent hedge fund indices based, for example, on fund age.

(3) We find that the investment success of hedge fund managers decreases over time, for varying reasons. For example, hedge fund returns are path-dependent. In the 
context of hedge fund lifecycles, a hedge

fund should thus be considered an

enterprise. While traditional investment

funds of large corporations may be able to

change fund managers easily over time, this

is not true for hedge funds, where the roles

of manager and owner are usually closely

intertwined. We thus suggest that

qualitative diligence of hedge fund

managers within the scope of allocation

decisions is especially critical. In this

context, a future study could verify to what

extent our results for the hedge fund

lifecycle can be transferred to other asset

classes (eg equity or private equity funds).

\section{Reference and Notes}

1 Fama, E. (1970) 'Efficient Capital Markets: A Review of Theory and Empirical Work', Journal of Finance, Vol. 25, No. 2, pp. 383-417.

2 Jevons, W.S. (1871) 'The Theory of Political Economy', Macmillan \& Co., London.

3 Vernon, R. (1966) 'International Investment and International Trade in the Product Cycle', Quarterly Journal of Economics, Vol. 2, No. 2, pp. 190-207.

4 Keating, C. and Shadwick, W. (2002) 'Omega: A Universal Performance Measure', Journal of Performance Measurement, Vol. 6, No. 2, pp. 59-84.

5 Jensen, M.C. (1968) 'The Performance of Mutual Funds in the Period 1945-1964', Journal of Finance, Vol. 23, No. 2, pp. 389-416.

6 Agarwal, V. and Naik, N.Y. (2000) 'On Taking the Alternative Route: Risks, Rewards, and Performance Persistence of Hedge Funds', Journal of Alternative Investments, Vol. 2, No. 4, pp. 6-23.

7 Capocci, D., Corhay, A. and Hübner, G. (2005) 'Hedge Fund Performance and Persistence in Bull and Bear Markets', European Journal of Finance, Vol. 11, No. 5, pp. 361-392.

8 Harri, A. and Brorsen, B.W. (2002) 'Performance Persistence and the Source of Returns for Hedge Funds', Working Paper, Oklahoma State University.

9 Brown, S.J., Goetzmann, W.N. and Ibbotson, R. (1999) 'Offshore Hedge Funds: Survival and Performance 1989-1995', Journal of Business, Vol. 72, No. 1, pp. 91-117.

10 Kat, H.M. and Menexe, F. (2003) 'Persistence in Hedge Fund Performance: The True Value of a Track Record',
Journal of Alternative Investments, Vol. 5, No. 1, pp. 66-72.

11 Agarwal, V. and Naik, N.Y. (2000) 'Generalised Style Analysis of Hedge Funds', Journal of Asset Management, Vol. 1, No. 1, pp. 93-109.

12 Edwards, F.R. and Caglayan, M.O. (2001) 'Hedge Fund Performance and Manager Skill', Journal of Futures Markets, Vol. 21, No. 11, pp. 1003-1028.

13 Boyson, N. and Cooper, M. (2003) 'Do Hedge Funds Exhibit Performance Persistence? A New Approach', Working Paper, Northeastern University Boston.

14 Baquero, G., Horst, J.T. and Verbeek, M. (2004) 'Survival, Look-ahead Bias, and the Persistence in Hedge Fund Performance', Journal of Financial and Quantitative Analysis, Vol. 40, No. 3, pp. 493-518.

15 However, various academic articles have found that between 30 and 50 per cent of hedge funds will fail during their first three years.

16 Liang, B. (2001) 'Hedge Fund Performance: 19901999’, Financial Analyst Journal, Vol. 57, No. 1, pp. 11-18.

17 Schneeweis, T., Kazemi, H. and Martin, G. (2001) 'Understanding Hedge Fund Performance: Research Results and Results of Thumb for the Institutional Investor', Working Paper, University of Massachusetts.

18 Amenc, N., Curtis, S. and Martellini, L. (2003) 'The Alpha and the Omega of Hedge Fund Performance Measurement', Working Paper, Edhec Business School, Lille.

19 Kaiser, D.G. and Kisling, K. (2006) 'Einflussfaktoren der risikoadjustierten Wertentwicklung von Hedgefonds', in Busack, M. and Kaiser, D.G. (eds.) 'Handbuch Alternative Investments Band 1', Gabler Verlag, Wiesbaden.

20 Howell, M. (2001) 'Fund Age and Performance', Journal of Alternative Investments, Vol. 4, No. 1, pp. $57-60$.

21 Gregoriou, G.N. and Rouah, F. (2002) 'Large versus Small Hedge Funds: Does Size Affect Performance?', Journal of Alternative Investments, Vol. 5, No. 4, pp. 75-77.

22 These include fund administration, risk management, marketing, compliance, and trading.

23 Gregoriou, G.N. and Rouah, F. (2001) 'Do Stock Market Indices Move the Ten Largest Hedge Funds? A Cointegration Approach', Journal of Alternative Investments, Vol. 4, No. 3, pp. 61-66.

24 Note that, in this context, it is not possible to obtain high liquidity premiums when trading large positions in liquid markets. In contrast, it would be possible when trading small positions in illiquid markets.

25 Agarwal, V., Daniel, N.D. and Naik, N.Y. (2004) 'Flows, Performance, and Managerial Incentives in 
Hedge Funds', Working Paper, Georgia State University.

26 Goetzmann, W.N., Ingersoll, J.E. and Ross, S.A. (2003) 'High-Water Marks and Hedge Fund Management Contracts', Journal of Finance, Vol. 58, No. 4, pp. 16851718.

27 Getmansky, M. (2004) 'The Life Cycle of Hedge Funds: Fund Flows, Size and Performance', Working Paper, University of Massachusetts.

28 Ammann, M. and Moerth, P. (2005) 'Impact of Fund Size on Hedge Fund Performance', Journal of Asset Management, Vol. 6, No. 3, pp. 219-238.

29 Fung, W., Hsieh, D.A., Naik, N.Y. and Ramadorai, T. (2005) 'Hedge Funds: Performance, Risk and Capital Formation', Working Paper, London Business School.

30 In general, we assume that hedge funds will constantly receive new inflows over time if their investment goals are met. Hedge funds that fail to reach their goals are likely to cease operation. Hence, for simplicity, we assume equality between small and young hedge funds, and between old and large hedge funds.

31 Berk, J.B. and Green, R. (2004) 'Mutual Fund Flows and Performance in Rational Markets', Journal of Political Economy, Vol. 112, No. 6, pp. 1269-1295.

32 De Figueiredo, R. and Budhraja, V. (2006) 'Hedge Funds: Built to Last?', Citigroup Alternative Investments Journal, Vol. 1, No. 1, pp. 2-13.

33 Eicher, T.S. and Kim, S.C. (2004) 'Market Structure and Innovation Revisited: Endogenous Productivity, Training and Market Shares', in Boldrin, M., Chen, B.L. and Wang, P. (eds.) 'Human Capital, Trade and Public Policy in Rapidly Growing Economies', Edward Elgar, New York.

34 Jones, C.I. (1995) 'R\&D-Based Models of Economic Growth', Journal of Political Economy, Vol. 105, No. 4, pp. 759-784.
35 Bacmann, J.-F. and Bosshard, U. (2006) 'Optimising Hedge Fund Portfolios with Omega Functions', in Gregoriou, G.N. and Kaiser, D.G. (eds.) 'Hedge Funds and Managed Futures - A Handbook for Institutional Investors', Risk Books, London.

36 Schneeweis, T., Kazemi, H. and Gupta, R. (2004) 'Omega and Performance Measurement', Journal of Performance Measurement, Vol. 8, No. 3, pp. 42-54.

37 This step is necessary to achieve statements about the lifecycle and to reach a sufficiently large sample size within the individual strategies.

38 Fung, W. and Hsieh, D.A. (2000) 'Performance Characteristics of Hedge Funds and Commodity Funds: Natural vs. Spurious Biases', Journal of Financial and Quantitative Analysis, Vol. 35, No. 3, pp. 291-307.

39 Füss, R. and Kaiser, D.G. (2007) 'The Tactical and Strategic Value of Hedge Fund Strategies: A Cointegration Approach', Financial Markets and Portfolio Management, Vol. 21, No. 4, pp. 425-444.

40 Füss, R., Kaiser, D.G. and Adams, Z. (2007) 'Value at Risk, GARCH Modelling and the Forecasting of Hedge Fund Return Volatility', Journal of Derivatives and Hedge Funds, Vol. 13, No. 1, pp. 2-25.

41 A polynomial trend line is a curve that represents the development of a return time series. It is calculated according to the least-squares method, which makes it easier to recognise trends. To quantify statements about the conformity of the trend line with actual developments, we add the coefficient of determination $\left(R^{2}\right)$ to the equations.

42 Each fund in its starting month was compared with other funds in their starting months. Every fund in its second month was compared with other funds in their second months. 